\title{
Modelos organizacionais e reformas da administração pública*
}

\author{
Leonardo Secchi**
}

SuMÁrio: 1. Introdução; 2. O modelo burocrático; 3. Gerencialismo; 4. Governança pública; 5 . Comparando modelos organizacionais: continuidade ou descontinuidade? 6. Considerações finais.

Summary: 1. Introduction; 2. The bureaucratic model; 3. Managerialism; 4. Public governance; 5 . Comparing the organizational models: continuity or discontinuity? 6. Final remarks.

Palavras-chave: reforma da administração pública; modelo burocrático; administração pública gerencial; governo empreendedor; governança pública.

KEY wORDs: public management reforms; bureaucratic model; new public management; entrepreneurial government; public governance.

Este artigo foi elaborado a partir de uma pesquisa bibliográfica em livros e artigos científicos clássicos ou recentemente publicados na literatura de administração pública na Europa e nos Estados Unidos, e faz uma comparação dos quatro modelos organizacionais e relacionais que vêm inspirando o desenho das estruturas e processos nas recentes reformas da administração pública. Os modelos analisados são o burocrático, a administração pública gerencial, o governo empreendedor e a governança pública. Recentemente, reformas administrativas vêm pregando a substituição progressiva do modelo burocrático weberiano por novos modelos de gestão

\footnotetext{
* Artigo recebido em ago. 2008 e aceito em jan. 2009. O autor agradece a Gloria Regonini (Università degli Studi di Milano), Fiorenzo Girotti (Università degli Studi di Torino), Joan Subirats (Universidad Autónoma de Barcelona), John D. Donahue (Harvard University) e Samuel Tyler (Boston Municipal Research Bureau). E também à Capes pela bolsa de pesquisa de doutorado.

** PhD em ciências políticas pela Universidade de Milão, Itália, M.Sc. em administração pela Universidade Federal de Santa Catarina, bacharel em administração pela Universidade Federal de Santa Catarina. Professor de administração do Centro de Ciências Sociais Aplicadas da Universidade Comunitária Regional de Chapecó (Unochapecó), editor-responsável da revista Gestão Organizacional, líder do Grupo de Pesquisa em Gestão Social da Unochapecó. Endereço: Av. Senador Attilio Fontana, 591-E - Bairro Efapi — CEP 89809-000, Chapecó, SC, Brasil. E-mail: leonardo@unochapeco.edu.br.
} 
e de relação do Estado com a sociedade. Este artigo mostra que os novos modelos compartilham características essenciais com o modelo tradicional burocrático e, portanto, não são modelos de ruptura. Também é argumentado que reformas da administração pública transformam-se facilmente em políticas simbólicas, e que políticos e burocratas tentam manipular a percepção do público em relação ao desempenho dos governos. Não são raros os esforços de reforma da administração pública que avançam mais em autopromoção e retórica do que em fatos concretos. Por último, são feitas sugestões para uma agenda de pesquisa àqueles interessados em temas de reformas da administração pública.

\section{Organizational models and public management reforms}

This article is based on a bibliographical research both in classic and recently published textbooks and in scientific papers in the literature of public administration in Europe and the United States. Its main objective is to compare the four organizational and relational models that have been inspiring the design of structures and processes in recent public management reforms: the bureaucratic model, the new public management, the entrepreneurial government, and public governance. Recently, there has been a progressive shift from the bureaucratic model to these new organizational and relational models. This article demonstrates that new organizational and relational models share important characteristic with the traditional bureaucratic model and, therefore, are not models of rupture. Also, public management reforms can easily become symbolic policies when politicians and public officials strive to manipulate the public's perception of the administration's performance. Public management reform efforts related to self-promotion and rhetoric rather than to concrete results are a common fact. Finally, the article proposes items for a research agenda for those who are interested in public management.

\section{Introdução}

Desde os anos 1980, as administrações públicas em todo o mundo realizaram mudanças substanciais nas políticas de gestão pública (PGPs) e no desenho de organizações programáticas (DOPs). Essas reformas administrativas consolidam novos discursos e práticas derivadas do setor privado e os usam como benchmarks para organizações públicas em todas as esferas de governo. Hays e Plagens (2002:327) dão uma noção da magnitude dessas reformas: "estratégias aclamadas de reforma têm vindo diretamente do setor privado numa onda que talvez possa ser considerada a mais profunda redefinição da administração pública desde que esta emergiu como uma área de especialidade identificável". ${ }^{1}$

\footnotetext{
${ }^{1}$ Tradução livre a partir do original.
} 
Os elementos apontados como ativadores dessas ondas de "modernização" são a crise fiscal do Estado (Aucoin, 1990; Hood, 1995; Pollitt e Bouckaert 2002a), a crescente competição territorial pelos investimentos privados e mão de obra qualificada (Subirats e Quintana, 2005), a disponibilidade de novos conhecimentos organizacionais e tecnologia, a ascensão de valores pluralistas e neoliberais (Kooiman, 1993; Rhodes, 1997), e a crescente complexidade, dinâmica e diversidade das nossas sociedades (Kooiman, 1993). No velho continente, o processo de europeanização também tem desempenhado um papel crucial no estímulo à adoção de novos modelos organizacionais e à revisão das PGPs nos níveis nacionais, regionais e municipais (Olsen, 2002; Radaelli, 2005).

O modelo burocrático tornou-se o alvo das mais ásperas críticas. O modelo burocrático weberiano foi considerado inadequado para o contexto institucional contemporâneo por sua presumida ineficiência, morosidade, estilo autorreferencial, e descolamento das necessidades dos cidadãos (Barzelay, 1992; Osborne e Gaebler, 1992; Hood, 1995; Pollitt e Bouckaert, 2002a).

Dois modelos organizacionais e um paradigma relacional foram apresentados como alternativas ao modelo burocrático. A administração pública gerencial (AGP) e o governo empreendedor (GE) são modelos organizacionais que incorporam prescrições para a melhora da efetividade da gestão das organizações públicas. O movimento da governança pública (GP) se traduz em um modelo relacional porque oferece uma abordagem diferenciada de conexão entre o sistema governamental e o ambiente que circunda o governo.

No longo prazo, esses modelos para reformas têm potencial para mudar o modo que as organizações públicas se administram e se relacionam. Também é importante frisar que, não raras vezes, reformas da administração pública são empunhadas com meros propósitos retóricos. Outras vezes, têm poucos efeitos ou fracassam completamente.

Este artigo apresenta o estado da arte sobre modelos organizacionais públicos recentemente debatidos na comunidade epistêmica internacional da área de administração pública. Além de organizar a literatura sobre modelos organizacionais, o artigo compara elementos essenciais dos modelos, avançando na discussão sobre os pontos de inflexão e os pontos de continuidade das recentes propostas de modelos para reformas administrativas.

Este artigo foi elaborado por meio de pesquisa bibliográfica realizada em livros, artigos científicos e working papers da literatura de administração pública, publicados na Europa e nos Estados Unidos. A comparação dos modelos organizacionais foi feita utilizando alguns "conceitos sensíveis" (Patton, 1990), tais como função sistêmica, relação sistêmica com o ambiente, sepa- 
ração entre política e administração, função administrativa essencial, discricionariedade administrativa e tipo de tratamento que a administração pública tem com o cidadão.

Nas próximas seções serão apresentados os modelos organizacionais diretamente relacionados com os recentes esforços de reformas administrativas: o modelo burocrático, o gerencialismo (subdividido em APG e GE) e a governança pública. Por fim, será feita a análise comparativa dos modelos em questão.

\section{0 modelo burocrático}

O modelo burocrático weberiano é um modelo organizacional que desfrutou notável disseminação nas administrações públicas durante o século XX em todo o mundo. $\mathrm{O}$ modelo burocrático é atribuído a Max Weber, porque o sociólogo alemão analisou e sintetizou suas principais características. O modelo também é conhecido na literatura inglesa como progressive public administration - PPA (Hood, 1995), referindo-se ao modelo que inspirou as reformas introduzidas nas administrações públicas dos Estados Unidos entre os séculos $\mathrm{XIX}$ e XX, durante a chamada progressive era.

No entanto, desde o século XVI o modelo burocrático já era bastante difundido nas administrações públicas, nas organizações religiosas e militares, especialmente na Europa. Desde lá o modelo burocrático foi experimentado com intensidades heterogêneas e em diversos níveis organizacionais, culminando com sua adoção no século XX em organizações públicas, privadas e do terceiro setor.

Em 1904, no livro A ética protestante e o espírito do capitalismo, Max Weber (1930:16-17) fazia referências ao burocrata como profissional e à disseminação do modelo burocrático em países ocidentais, suas características de especialização, controle, e, sobretudo, racionalismo.

No country and no age has ever experienced, in the same sense as the modern Occident, the absolute and complete dependence of its whole existence, of the political, technical, and economic conditions of its life, on a specially trained organization of officials. The most important functions of the everyday life of society have come to be in the hands of technically, commercially, and above all legally trained government officials. (...) In fact, the State itself, in the sense of a political association with a rational, written constitution, rationally ordained law, and an administration bound to rational rules or laws, administered by trained officials, 
is known, in this combination of characteristics, only in the Occident, despite all other approaches to it.

Foi apenas após a morte de Weber, e após a publicação em 1922 do livro Wirtschaft und Gesellschaft (Economia e sociedade), que as bases teóricas da burocracia foram definitivamente construídas. Na sua descrição sobre os modelos ideais típicos de dominação, Weber identificou o exercício da autoridade racional-legal como fonte de poder dentro das organizações burocráticas. Nesse modelo, o poder emana das normas, das instituições formais, e não do perfil carismático ou da tradição.

A partir desse axioma fundamental derivam-se as três características principais do modelo burocrático: a formalidade, a impessoalidade e o profissionalismo.

A formalidade impõe deveres e responsabilidades aos membros da organização, a configuração e legitimidade de uma hierarquia administrativa, as documentações escritas dos procedimentos administrativos, a formalização dos processos decisórios e a formalização das comunicações internas e externas. As tarefas dos empregados são formalmente estabelecidas de maneira a garantir a continuidade do trabalho e a estandardização dos serviços prestados, para evitar ao máximo a discricionariedade individual na execução das rotinas.

A impessoalidade prescreve que a relação entre os membros da organização e entre a organização e o ambiente externo está baseada em funções e linhas de autoridade claras. O chefe ou diretor de um setor ou departamento tem a autoridade e responsabilidade para decidir e comunicar sua decisão. $\mathrm{O}$ chefe ou diretor é a pessoa que formalmente representa a organização. Ainda mais importante, a impessoalidade implica que as posições hierárquicas pertencem à organização, e não às pessoas que a estão ocupando. Isso ajuda a evitar a apropriação individual do poder, prestígio, e outros tipos de benefícios, a partir do momento que o indivíduo deixa sua função ou a organização.

O profissionalismo está intimamente ligado ao valor positivo atribuído ao mérito como critério de justiça e diferenciação. As funções são atribuídas a pessoas que chegam a um cargo por meio de competição justa na qual os postulantes devem mostrar suas melhores capacidades técnicas e conhecimento. O profissionalismo é um princípio que ataca os efeitos negativos do nepotismo que dominava o modelo pré-burocrático patrimonialista (March, 1961; Bresser-Pereira, 1996). A promoção do empregado para postos mais altos na hierarquia depende da experiência na função (senioridade) e desempenho (performance). O ideal é a criação de uma hierarquia de competências com 
base na meritocracia. Outras características do modelo que derivam do profissionalismo são a separação entre propriedade pública e privada, trabalho remunerado, divisão racional das tarefas e separação dos ambientes de vida e trabalho. Segundo Weber (1992:223)

experience tends universally to show that the purely bureaucratic type of administration (...) is, from a purely technical point of view, capable of attaining the highest degree of efficiency and is in this sense formally the most rational known means of exercising authority over human beings. It is superior to any other form in precision, in stability, in the stringency of its discipline, and in its reliability.

O modelo burocrático weberiano estabeleceu um padrão excepcional de expertise entre os trabalhadores das organizações. Um dos aspectos centrais é a separação entre planejamento e execução. Com base no princípio do profissionalismo e da divisão racional do trabalho, a separação entre planejamento e execução dá contornos práticos à distinção wilsoniana entre a política e a administração pública, na qual a política é responsável pela elaboração de objetivos e a administração pública responsável por transformar as decisões em ações concretas. No setor privado, a burocracia weberiana consolida a prescrição de Taylor (1911) sobre divisão de tarefas entre executivos (usando a mente) e operadores (usando os músculos).

A preocupação com a eficiência organizacional é central no modelo burocrático. Por um lado, os valores de eficiência econômica impõem a alocação racional dos recursos, que na teoria weberiana é traduzida em uma preocupação especial com a alocação racional das pessoas dentro da estrutura organizacional. Por outro lado, o valor da eficiência administrativa induz à obediência às prescrições formais das tarefas, em outras palavras, preocupações do "como as coisas são feitas". Nas teorias da escolha pública (public choice) os mecanismos que induzem a burocracia a cumprir determinadas tarefas seguindo prescrições formais são chamados restrições ex ante (ex ante constraints) às agências e/ou burocracias (McCubbins, Noll e Weingast, 1989).

Outro valor implícito na ideia de burocracia é a equidade, pois ela é desenhada para dar tratamento igualitário aos empregados que desempenham tarefas iguais (tratamento, salários etc.). A burocracia também é desenhada para prover produtos e serviços standard aos destinatários de suas atividades.

Também implícita ao modelo burocrático é a desconfiança geral com relação à natureza humana. O controle procedimental de tarefas, e reiteradas 
preocupações com a imparcialidade no tratamento dos empregados e clientes

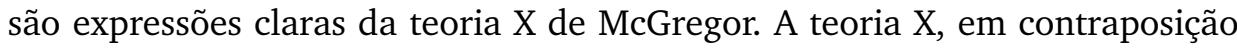
à teoria $Y$ do mesmo McGregor, é entendida como desconfiança com relação à índole humana, à vontade de trabalho e desenvolvimento das pessoas, e à capacidade criativa e de responsabilidade.

As críticas ao modelo organizacional burocrático são muitas. Após a II Guerra Mundial uma onda de confrontação intelectual contra o modelo burocrático foi liderada por Simon (1947), Waldo (1948) e Merton (1949).

Robert Merton (1949) elaborou a crítica mais incisiva e direta ao modelo burocrático, analisando os seus efeitos negativos sobre as organizações e outras esferas da vida. Esses efeitos negativos foram chamados de disfunções burocráticas: o impacto da prescrição estrita de tarefas (red tape) sobre a motivação dos empregados, resistência às mudanças, e o desvirtuamento de objetivos provocado pela obediência acrítica às normas. Outro aspecto levantado por Merton (1949) é o abuso da senioridade como critério para promoção funcional que, segundo o pesquisador, pode frear a competição entre funcionários e fomentar um senso de integridade e corporativismo entre os funcionários, causando um destacamento dos interesses dos destinatários/clientes dos serviços da organização. Ademais, a impessoalidade levada ao pé da letra pode levar a organização a não dar atenção a peculiaridades das necessidades individuais. Merton (1949) ainda enumera a arrogância funcional em relação ao público destinatário, em especial no serviço público, pois, em muitos casos, o funcionalismo público goza de situação de monopólio na prestação de serviços. Tais disfunções podem ser ainda mais prejudiciais em organizações que dependem da criatividade e da inovação.

Depois de Merton, outras críticas foram feitas ao modelo burocrático, e elas podem ser notadas implicitamente nas características dos chamados modelos pós-burocráticos de organização. Na administração pública destacam-se os modelos gerenciais (APG e GE), e a governança pública.

\section{Gerencialismo}

Dois modelos organizacionais têm pintado o quadro global de reformas da administração pública nas últimas décadas: a administração pública gerencial (APG) e o governo empreendedor (GE). Os dois modelos compartilham os valores da produtividade, orientação ao serviço, descentralização, eficiência na 
prestação de serviços, marketization ${ }^{2}$ e accountability $^{3}$ (Kettl, 2005). A APG e o GE são frequentemente chamados de gerencialismo (managerialism).

A administração pública gerencial ou nova gestão pública (new public management) é um modelo normativo pós-burocrático para a estruturação e a gestão da administração pública baseado em valores de eficiência, eficácia e competitividade.

Alguns autores se referem à APG como um movimento delimitado em espaço e tempo, como um processo de mudança nas administrações públicas do norte da Europa, do Canadá, e na Oceania nos anos 1980 e 90 (Christensen, Lagreid e Wise, 2002; Kettl, 2005).

De acordo com Barzelay (2000:229), a APG é um campo de debate acadêmico e profissional sobre temas de "políticas de gestão pública, liderança executiva, desenho de organizações programáticas e operações de governo". ${ }^{4}$ Outros autores ainda consideram a APG um conjunto de ferramentas e não uma ideologia, tendência ou movimento (Schedler, citado por Jones, 2004).

Hood e Jackson (1991) defendem que a APG é um argumento administrativo ou uma filosofia de administração, na qual eficiência e desempenho são valores que prevalecem. Essa filosofia de administração é baseada em um conjunto de doutrinas e justificativas. As doutrinas são prescrições para a ação, receitas para serem aplicadas na gestão e no desenho das organizações públicas. As justificativas são as razões para a pertinência das doutrinas, dando a elas um sentido racional. Como argumentado por Hood e Jackson (1991), doutrinas e justificativas são relativamente coerentes umas com as outras, e algumas filosofias podem usar certas prescrições baseadas em algumas justificativas, já outras filosofias podem usar as mesmas prescrições baseadas em justificativas totalmente diferentes.

As justificativas são compostas por valores, frequentemente parciais e contestáveis, mas com força normativa. De acordo com Hood e Jackson (1991), existem três grupos de valores que dão base às justificativas:

\footnotetext{
${ }^{2}$ Marketization é o termo utilizado para a utilização de mecanismos de mercado dentro da esfera pública. Exemplos de mecanismos de mercado é a liberdade de escolha de provedor por parte do usuário do serviço público e a introdução da competição entre órgãos públicos e entre órgãos públicos e agentes privados.

${ }^{3}$ Accountability é um termo de difícil tradução para o português. Literalmente accountability significa a prestação de contas por parte de quem foi incumbido de uma tarefa àquele que solicitou a tarefa (relação entre o agente e o principal). A Accountability pode ser considerada o somatório dos conceitos de responsabilização, transparência e controle.

${ }^{4}$ Tradução livre a partir do original.
} 
- grupo sigma - eficiência e alocação racional de recursos, limitação do desperdício, simplicidade e clareza;

- grupo theta - equidade, justiça, neutralidade, accountability e controle de abusos dos agentes (desonestidade, imperícia etc.);

v grupo lambda: capacidade de resposta, resiliência sistêmica, flexibilidade, elasticidade.

Barzelay (2000) e Parsons (2006) afirmam que a APG é um modelo normativo para a gestão pública, fundado em argumentos, doutrinas e justificativas derivados da interpretação positiva ao grupo sigma de valores.

A interpretação de APG como doutrina é compartilhada por Pollitt e Bouckaert (2002b) e por Hood (1995). Para Pollitt e Bouckaert (2002b), a APG pode ser considerada uma religião, um sistema de crenças baseado na racionalidade instrumental aplicada à gestão pública. Hood (1995:95-98) avançou a discussão enumerando o conjunto de prescrições operativas da APG:

- desagregação do serviço público em unidades especializadas, e centros de custos;

- competição entre organizações públicas e entre organizações públicas e privadas;

v uso de práticas de gestão provenientes da administração privada;

v atenção à disciplina e parcimônia;

$\checkmark$ administradores empreendedores com autonomia para decidir;

v avaliação de desempenho;

v avaliação centrada nos outputs.

O livro Reinventando o governo, escrito por Osborne e Gaebler em 1992, inaugurou o "governo empreendedor" como um estilo pragmático de gestão pública.

A abordagem foi claramente inspirada na teoria administrativa moderna, trazendo para os administradores públicos a linguagem e ferramentas da administração privada contida em livros como The practice of management (Drucker, 1954) e In search of excellence (Peters e Waterman, 1982). Originalmente, as ideias do GE se desenvolveram com maior intensidade nos Estados Unidos, quando a abordagem de Osborne e Gaebler foi utilizada no programa de governo do partido democrático nas eleições presidenciais de 1992, e pos- 
teriormente usada como base para o Government performance results act de 1993 e o programa nacional de desempenho da administração pública (national performance review) durante a administração Clinton-Gore.

Fazendo uso de uma linguagem prescritiva, Osborne e Gaebler (1992) sintetizaram em uma lista de 10 mandamentos a receita para transformar uma organização pública burocrática em uma organização pública racional e eficaz. Os dez mandamentos do GE são apresentados de forma resumida a seguir:

V governo catalisador - os governos não devem assumir o papel de implementador de políticas públicas sozinhos, mas sim harmonizar a ação de diferentes agentes sociais na solução de problemas coletivos;

- governo que pertence à comunidade — os governos devem abrir-se à participação dos cidadãos no momento de tomada de decisão;

v governo competitivo - os governos devem criar mecanismos de competição dentro das organizações públicas e entre organizações públicas e privadas, buscando fomentar a melhora da qualidade dos serviços prestados. Essa prescrição vai contra os monopólios governamentais na prestação de certos serviços públicos;

- governo orientado por missões - os governos devem deixar de lado a obsessão pelo seguimento de normativas formais e migrar a atenção na direção da sua verdadeira missão;

v governo de resultados - os governos devem substituir o foco no controle de inputs para o controle de outputs e impactos de suas ações, e para isso adotar a administração por objetivos;

v governo orientado ao cliente - os governos devem substituir a autorreferencialidade pela lógica de atenção às necessidades dos clientes/cidadãos;

v governo empreendedor - os governos devem esforçar-se a aumentar seus ganhos por meio de aplicações financeiras e ampliação da prestação de serviços;

V governo preventivo - os governos devem abandonar comportamentos reativos na solução de problemas pela ação proativa, elaborando planejamento estratégico de modo a antever problemas potenciais;

v governo descentralizado - os governos devem envolver os funcionários nos processos deliberativos, aproveitando o seu conhecimento e capacidade inovadora. Além de melhorar a capacidade de inovação e resolução de pro- 
blemas, a descentralização também é apresentada como forma de aumentar a motivação e autoestima dos funcionários públicos;

- governo orientado para o mercado - os governos devem promover e adentrar na lógica competitiva de mercado, investindo dinheiro em aplicações de risco, agindo como intermediário na prestação de certos serviços, criando agências regulatórias e institutos para prestação de informação relevante e, assim, abatendo custos transacionais.

Se observados atentamente, uns mandamentos se sobrepõem a outros, como nos casos dos mandamentos de governo de resultados e governo orientado por missões. Nos mandamentos de governo catalisador, governo orientado para o mercado, governo empreendedor e governo competitivo, os autores apresentam prescrições contraditórias em relação a papel e tamanho do setor público. Apesar disso, o livro mostra coerência em valores primários de racionalidade, eficácia e liberdade de escolha.

Implicitamente, o modelo de GE de Osborne e Gaebler tem uma perspectiva positiva com relação à natureza humana. Os autores, especialmente nos capítulos dois (governo que pertence à comunidade) e nove (governo descentralizado), defendem uma visão quase romântica com relação ao comportamento e motivação dos cidadãos e funcionários pelos temas públicos. As ideias de Osborne e Gaebler também exaltam valores ligados ao filão filosófico do comunitarismo, principalmente quando evocam a importância do envolvimento cívico no processo de mudança, comunicação e parceria entre esferas públicas e privadas.

\section{Governança pública}

A definição de governança não é livre de contestações. Isso porque tal definição gera ambiguidades entre diferentes áreas do conhecimento. As principais disciplinas que estudam fenômenos de "governance" são as relações internacionais, teorias do desenvolvimento, a administração privada, as ciências políticas e a administração pública.

Estudos de relações internacionais concebem governança como mudanças nas relações de poder entre estados no presente cenário internacional. Os chamados teóricos globalizadores (globalizers), de tradição liberal, veem governance como a derrocada do modelo de relações internacionais vigente desde o século XVII, onde o Estado-nação sempre foi tido como ator indivi- 
dual, e a transição a um modelo colaborativo de relação interestatal e entre atores estatais e não estatais na solução de problemas coletivos internacionais. Governança, nesse sentido, denota o processo de estabelecimento de mecanismos horizontais de colaboração para lidar com problemas transnacionais como tráfico de drogas, terrorismo e emergências ambientais.

Teorias do desenvolvimento tratam a governança como um conjunto adequado de práticas democráticas e de gestão que ajudam os países a melhorar suas condições de desenvolvimento econômico e social. ${ }^{5}$ "Boa governança" é, portanto, a combinação de boas práticas de gestão pública. O Fundo Monetário Internacional (FMI) e o Banco Mundial exigem "boa governança" como requisito para países em via de desenvolvimento receberem recursos econômicos e apoio técnico. Áreas de aplicação das boas práticas são aquelas envolvidas na melhora da eficiência administrativa, da accountability democrática, e de combate à corrupção como exemplos de "elementos essenciais de um framework no qual economias conseguem prosperar"6 (IMF, 2003:1).

Governança na linguagem empresarial e contábil significa um conjunto de princípios básicos para aumentar a efetividade de controle por parte de stakeholders e autoridades de mercado sobre organizações privadas de capital aberto. Exemplos de princípios institucionais de governança são: a articulação entre autoridades para controlar o respeito à legislação e a garantia de integridade e objetividade pelas autoridades reguladoras do mercado. Exemplos de princípios de governança para empresas privadas são: a participação proporcional de acionistas na tomada de decisão estratégica, a cooperação de empresas privadas com organizações externas (sindicatos, credores etc.) e stakeholders internos (empregados), além de transparência nas informações e responsabilização dos executivos do quadro dirigente perante os acionistas (OECD, 2004).

A interpretação de governança adotada neste artigo é a derivada das ciências políticas e administração pública, como um modelo horizontal de relação entre atores públicos e privados no processo de elaboração de políticas públicas (Kooiman,1993; Richards e Smith, 2002).

A etiqueta "governance" denota pluralismo, no sentido que diferentes atores têm, ou deveriam ter, o direito de influenciar a construção das políticas públicas. Essa definição implicitamente traduz-se numa mudança do papel do Estado

\footnotetext{
${ }^{5}$ Este modelo explicativo é oposto à teoria da modernização (Lipset, 1959) na qual o desenvolvimento econômico é proposto como variável independente e a democracia como variável dependente. Na modernization theory, a ascensão e consolidação de regime democrático em um país dependem do alcance de certo patamar de desenvolvimento econômico.

${ }^{6}$ Tradução livre a partir do original.
} 
(menos hierárquico e menos monopolista) na solução de problemas públicos. Por causa disso, a governança pública (GP) também é relacionada ao neoliberalismo. A GP também significa um resgate da política dentro da administração pública, diminuindo a importância de critérios técnicos nos processos de decisão e um reforço de mecanismos participativos de deliberação na esfera pública.

Os impulsionadores do movimento da GP são múltiplos. O primeiro é que "a crescente complexidade, dinâmica e diversidade de nossas sociedades coloca os sistemas de governo sob novos desafios e que novas concepções de governança são necessárias"7 (Kooiman, 1993:6). A segunda força por trás da GP é a ascensão de valores neoliberais e o chamado esvaziamento do Estado (hollowing out of the state), em que a incapacidade do Estado em lidar com problemas coletivos é denunciada. Tal movimento ideológico desconfia da habilidade estatal de resolver seus próprios problemas de forma autônoma e prega a redução das autoridades nacionais em favor de organizações internacionais (blocos regionais, Nações Unidas, FMI, Banco Mundial), em favor de organizações não estatais (mercado e organizações não governamentais) e em favor de organizações locais (governos locais, agências descentralizadas etc.)

A terceira força motriz da GP é a própria APG como modelo de gestão da administração pública nacional, estadual e municipal, focando maior atenção no desempenho e no tratamento dos problemas do que nas perguntas "quem" deve implementar ou "como" devem ser implementadas as políticas públicas. Na verdade, alguns acadêmicos consideram a GP uma consequência do movimento da APG, com a qual compartilha algumas características: "há alguma semelhança entre as duas perspectivas e parece claro que o recente interesse em governança, em parte, tem sido alavancado pela crescente popularidade da administração pública gerencial e a idéia de formas genéricas de controle social" 8 (Pierre e Peters, 2000: 65).

Pierre e Peters (2000) delineiam os elementos inexoráveis da GP: estruturas e interações. As estruturas podem funcionar por meio de mecanismos de hierarquia (governo), mecanismos autorregulados (mercado) e mecanismos horizontais de cooperação (comunidade, sociedade, redes). As interações dos três tipos de estrutura são fluidas, com pouca ou nenhuma distinção clara entre elas.

Essa abordagem relacional, e o resgate das redes/comunidades/sociedades como estruturas de construção de políticas públicas, é a grande novidade proposta pelos teóricos da GP. Segundo Brugué e Vallès (2005:198):

\footnotetext{
${ }^{7}$ Tradução livre a partir do original.

${ }^{8}$ Id.
} 
A governança (...) não é mais baseada na autoridade central ou políticos eleitos (modelo da hierarquia) e nem passagem de responsabilidade para o setor privado (modelo de mercado), mas sim regula e aloca recursos coletivos por meio de relações com a população e com outros níveis de governo. ${ }^{9}$

Um aspecto de maior discordância dentro da comunidade epistêmica de administração pública é a questão do papel do Estado num contexto de GP. Por um lado, Kooiman (1993) percebe uma diminuição do protagonismo estatal no processo de elaboração de políticas públicas. De acordo com Kooiman, a GP implica não apenas o envolvimento de atores não estatais no planejamento e implementação das políticas públicas, mas também em todo o processo de coprodução e cogestão de políticas. Rhodes (1997:57) compartilha desta visão, afirmando que "o Estado torna-se uma coleção de redes interorganizacionais compostas por atores governamentais e sociais sem nenhum ator soberano capaz de guiar e regular". ${ }^{10}$

Richards e Smith (2002) contestam esse tipo de entendimento, respondendo que o Estado mantém seu papel de liderança na elaboração de políticas públicas. De acordo com os autores, a GP provoca a criação de centros múltiplos de elaboração da política pública, em nível local, regional, nacional ou supranacional. O Estado, no entanto, não perde importância, mas sim desloca seu papel primordial da implementação para a coordenação e o controle.

Essa abordagem centrada no Estado argumenta que a GP cria "instrumentos de colaboração e um modelo mais transparente e integrador de Estado (...) que serve como um veículo ao alcance de interesses coletivos"11 (Pierre e Peters, 2000:92).

Tratando de questões mais práticas, a GP disponibiliza plataformas organizacionais para facilitar o alcance de objetivos públicos tais como o envolvimento de cidadãos na construção de políticas, fazendo uso de mecanismos de democracia deliberativa e redes de políticas públicas. ${ }^{12}$

A democracia deliberativa foi experimentada em indústrias japonesas no pós-guerra como um procedimento adequado a aproveitar o conhecimento e os frames cognitivos dos empregados no momento de decidir sobre pro-

\footnotetext{
${ }^{9}$ Tradução livre a partir do original.

${ }^{10}$ Id.

${ }^{11}$ Id.

${ }^{12}$ As redes de políticas públicas (policy networks) podem ser consideradas uma abordagem de pesquisa, uma filosofia de mediação de interesses ou uma forma específica de interação entre atores públicos e privados numa área de política pública (Börzel, 1998). A última interpretação é a que guia este artigo.
} 
dutos e processos produtivos (Sabel, 2001). Essa experiência organizacional também vem sendo usada na esfera governamental com o intuito de melhorar a interação entre atores públicos e privados para a solução de problemas coletivos e a redução de elos na cadeia de accountability. Os mecanismos de democracia deliberativa já foram experimentados em diferentes lugares e áreas de políticas públicas. Exemplos desses mecanismos são o fortalecimento da comunidade na gestão do patrimônio público (community empowerment), os planejamentos e orçamentos participativos, os conselhos deliberativos nas diversas áreas de políticas públicas.

As redes de políticas públicas (policy networks) representam outra forma específica de interação entre atores públicos e privados (Börzel, 1998). A participação nas redes de políticas públicas é aberta a qualquer interessado e tal tipo de arena produz baixa externalidade negativa ao ambiente externo (Regonini, 2005). Um exemplo de rede desse gênero seria o grupo de jovens que se organiza para resolver o problema de cachorros abandonados nos grandes centros urbanos, ou ainda o grupo de empresários e organizações do terceiro setor que se organizam para encontrar soluções locais para combater a criminalidade. A relativa independência das redes de políticas públicas é sublinhada por Rhodes (1997:52) quando diz que as “(...) redes de políticas públicas se auto-organizam. Trocando em miúdos, auto-organização quer dizer que as redes são autônomas e autogovernáveis (...), redes se desvinculam da liderança governamental, desenvolvem suas próprias políticas e moldam seus ambientes". ${ }^{13} \mathrm{O}$ ideal subjacente a essa forma de organização é a substituição da agregação numérica de preferências (votos) pelo processo cíclico e dialético de fertilização cruzada das preferências no momento de elaborar políticas públicas.

A GP também denota a coordenação de atores estatais e não estatais nas operações de governo, e as parcerias público-privadas (PPPs) são os exemplos mais básicos. A esse respeito Klijn e Teisman (2003:137) definem as PPPs como "cooperação entre atores públicos e privados de caráter temporário no qual os atores desenvolvem produtos mutuamente e/ou serviços e onde riscos, custos e benefícios são compartilhados". ${ }^{14}$ As áreas de políticas públicas onde as PPPs têm sido intensamente adotadas são os setores de infraestrutura e proteção ambiental, e os contratos preveem mecanismos de controle para mensurar resultados e impactos no ambiente econômico e social.

\footnotetext{
${ }^{13}$ Tradução livre a partir do original.

${ }^{14}$ Id.
} 


\section{Comparando modelos organizacionais: continuidade ou descontinuidade?}

A descrição dos modelos organizacionais de forma fragmentada parece obscurecer os elementos básicos de continuidade e descontinuidade. Além disso, a apresentação desses modelos de forma isolada, em "caixinhas", poderia levar a interpretações equivocadas quanto às fronteiras entre esses modelos. Serão apresentados aqui os elementos compartilhados e os elementos distintivos dos modelos burocráticos, do modelo gerencial (administração pública gerencial + governo empreendedor) e da governança pública, analisando conceitos sensíveis como função sistêmica, relação sistêmica com o ambiente, separação entre política e administração, função administrativa essencial, discricionariedade administrativa e tipo de tratamento que a administração pública tem com o cidadão.

O principal elemento comum desses modelos é a preocupação com a função controle. No caso do modelo burocrático, as características de formalidade e impessoalidade servem para controlar os agentes públicos, as comunicações, as relações intraorganizacionais e da organização com o ambiente. A função controle é uma consequência de um implícito julgamento de que os funcionários públicos se comportam de acordo com a teoria X de McGregor (1960). A função controle na APG está presente tanto no aspecto da capacidade de controle dos políticos sobre a máquina administrativa quanto no controle dos resultados das políticas públicas. O modelo relacional da GP dá valor positivo ao envolvimento de atores não estatais no processo de elaboração de políticas públicas como estratégia de devolver o controle aos destinatários das ações públicas (controle social). Usando a terminologia derivada da teoria sistêmica (Bertalanffy, 1969), esses modelos usam a função controle para manter a homeostase do sistema organizacional. Eles não são, portanto, modelos de ruptura.

O modelo burocrático e os modelos gerenciais compartilham a manutenção da distinção wilsoniana entre política e administração pública. A separação de funções entre política e administração permeia o modelo burocrático weberiano, em que o processo de construção da agenda pública é visto como tarefa eminentemente política, enquanto a implementação da política pública é de responsabilidade da administração. No gerencialismo, a responsabilidade sobre os resultados das políticas públicas recai sobre os ombros dos políticos. No entanto, a distinção entre política e administração é suavizada quando evoca a descentralização do poder de decisão, o envolvimento da comunidade e de burocratas no desenho das políticas públicas. Com base em valores 
pluralistas, a abordagem da GP apresenta elementos de descontinuidade e superação da distinção wilsoniana entre política e administração.

Como modelos organizacionais, a burocracia APG e o GE tratam questões de centralização e liberdade de decisão dos gestores. Para Hood (1995), evitar a discricionariedade de gestores públicos sempre foi uma marca característica da administração pública burocrática. A APG e o GE têm uma percepção mais positiva dos funcionários públicos, e como consequência os mecanismos de controle são desenhados para a avaliação de resultados, ao invés de controle de processo (Hood, 1995; Barzelay, 2001; Jones, 2004).

$\mathrm{O}$ tipo de relacionamento entre os ambientes internos e externos à organização pública é um ponto em comum entre os modelos gerenciais e o modelo de governança pública. Os modelos diferem da burocracia nesse aspecto. As esferas públicas e privadas são tratadas como impermeáveis no modelo burocrático weberiano, até como estratégia para enfrentar as ameaças de corrupção e patrimonialismo que assombravam as organizações pré-burocráticas. Nos preceitos da APG, do GE e da GP as fronteiras formais/legais do Estado tornam-se analiticamente impertinentes, tanto é que mecanismos de suavização da distinção das duas esferas são sugeridos como as práticas deliberativas, as redes de políticas públicas, as PPPs e o princípio de governo catalisador sugerido por Osborne e Gaebler (1992).

Uma clara distinção entre os três modelos em estudo é visível na forma de tratamento do cidadão. No modelo burocrático, o cidadão é chamado de usuário dos serviços públicos. Na retórica dos modelos APG e GE, os cidadãos são tratados como clientes, cujas necessidades devem ser satisfeitas pelo serviço público. Sob o guarda-chuva da GP, os cidadãos e outras organizações são chamados de parceiros ou stakeholders, com os quais a esfera pública constrói modelos horizontais de relacionamento e coordenação.

Outro critério que pode ser usado para diferenciar a PPA, a APG, o GE e a GP é o uso analítico das quatro funções clássicas de administração: planejamento, organização, direção e controle. ${ }^{15}$ Como já visto, a função controle está presente em todos os modelos organizacionais vistos. A função planejamento é especialmente enfatizada pela APG e GE no processo de planejamento estratégico, no acordo de objetivos entre políticos, burocratas e cidadãos e na adoção da administração por objetivos. O modelo burocrático coloca maior ênfase na

\footnotetext{
${ }^{15}$ As quatro funções administrativas são derivadas da contribuição original de Henri Fayol (1916), um engenheiro francês que sintetizou o papel dos administradores em funções de prévoir, organiser, commander, coordonner, contrôler.
} 
função organização: a análise e a descrição de cargos, a divisão racional das tarefas, a criação de fluxogramas e canais de comunicação entre departamentos e setores. Por último, a contribuição mais peculiar à governança é a função direção, entendida como a soma de liderança e atividades de coordenação. $O$ modelo relacional da GP põe ênfase na coordenação entre atores públicos e privados, e na capacidade de coordenação horizontal entre organizações públicas, organizações do terceiro setor, cidadãos, redes de políticas públicas e organizações privadas, na busca de soluções para problemas coletivos.

No quadro estão sintetizadas as distinções e similaridades entre os modelos organizacionais.

Características básicas dos modelos organizacionais

\begin{tabular}{|llll|}
\hline Característica & Burocracia & APG e GE & Governança Pública \\
\hline Função sistêmica & Homeostase & Homeostase & Homeostase \\
Relação sistêmica com o & Fechado & Aberto & Aberto \\
$\begin{array}{l}\text { ambiente } \\
\text { Distinção entre política e } \\
\text { administração }\end{array}$ & Separados & Trabalhando juntos sob & Distinção superada \\
$\begin{array}{l}\text { Funções administrativas } \\
\text { enfatizadas }\end{array}$ & $\begin{array}{l}\text { Controle e } \\
\text { organização }\end{array}$ & Controle e planejamento & Controle e \\
$\begin{array}{l}\text { Discricionariedade } \\
\text { administrativa }\end{array}$ & Baixa & Alta & n.a.* \\
Cidadão & Usuário & Cliente & Parceiro \\
\hline
\end{tabular}

* A GP dedica pouca atenção a assuntos organizacionais internos tais como autonomia dos gestores, descentralização vertical ou administrativa.

\section{Considerações finais}

Reforma da administração pública é o conjunto de inovações em políticas públicas de gestão e no desenho de organizações programáticas, e está baseada em um conjunto razoavelmente coerente de justificativas e retórica. Reformas da administração pública são geralmente alinhadas a valores de eficiência, accountability e flexibilidade (Hood e Jackson, 1991).

Uma reforma na administração pública acontece quando uma organização pública progressivamente muda suas práticas de gestão, modelo de relacionamento e retórica. Reformas da administração pública ocorrem em 
diferentes contextos espaciais e temporais, sob a guarda de diferentes escopos e valores.

No fim do século XIX nos Estados Unidos, e durante a década de 1930 no Brasil, reformas administrativas se espalharam pelas organizações públicas, marcando a transição de modelos pré-burocráticos para o modelo burocrático de administração pública (Bresser-Pereira, 1996, 2004). A mesma transição foi verificada em outros contextos e em outros períodos. Nas últimas três décadas, o modelo burocrático weberiano foi desafiado por novos modelos organizacionais e de relacionamento como a APG, o GE e a GP, e essa transição recente tem sido considerada uma nova onda global de reformas da administração pública (Kettl, 2005).

É importante lembrar que a presumida "mágica" das reformas administrativas deve ser cautelosa. Este artigo mostrou que novos modelos organizacionais compartilham algumas características com o modelo burocrático weberiano: continuam a colocar ênfase na função controle e não se apresentam como modelos de ruptura.

Outro cuidado que deve ser tomado é que as reformas da administração pública podem tornar-se facilmente políticas simbólicas de mero valor retórico (Gustaffson, 1983; March e Olsen, 1983; Battistelli, 2002). Políticos, funcionários de carreira e empreendedores políticos em geral tentam manipular a percepção coletiva a respeito das organizações públicas usando as reformas administrativas como argumento para isso. Não são raros os esforços de reforma da administração pública que avançam mais em autopromoção e retórica do que em fatos concretos.

Por fim, qualquer verificação empírica sobre reformas da administração pública deve estar atenta aos aspectos incrementais de mudança organizacional. Ao invés de falar em ascensão, predomínio e declínio de modelos organizacionais, talvez seja mais frutífero falar em um processo cumulativo de mudanças nas práticas e valores. Analiticamente um pesquisador pode encontrar fragmentos de burocracia, APG, GE e GP dentro de uma mesma organização. Até mesmo o patrimonialismo pré-burocrático ainda sobrevive por meio das evidências de nepotismo, gerontocracia, corrupção e nos sistemas de designação de cargos públicos baseados na lealdade política.

Ademais, entre organizações e dentro de uma mesma organização, o pesquisador pode encontrar ainda diferentes graus de penetração dos diversos modelos organizacionais. A pesquisa sobre a adoção de modelos organizacionais deve verificar continuidades e descontinuidades dos modelos em diferentes unidades organizacionais, níveis hierárquicos e regiões geográficas. 
Questões de pesquisa que parecem longe de estar respondidas na realidade brasileira são: até que ponto reformas da administração pública foram efetivadas empiricamente? Em quais níveis organizacionais e de decisão o aclamado aumento da discricionariedade gerencial vem acontecendo? Para que tipo de decisão os gestores intermediários gozam de liberdade (discricionariedade em como fazer ou discricionariedade no que fazer)? Existe realmente uma transição de mecanismos de controle em favor de mecanismos ex post, a despeito de controles de processo?

Tais questões parecem longe de um entendimento pacífico e o trabalho de pesquisa no campo poderá respondê-las apropriadamente se abordar as diversas esferas da administração pública, nas diversas áreas de políticas públicas, nas diversas regiões do país. Assim, são de extrema importância para o acúmulo de conhecimento a elaboração de estudos comparados, a organização de projetos interinstitucionais que estudem as questões, e a pesquisa usando a gramática e os esquemas analíticos já estabelecidos nas áreas de administração pública e políticas públicas (policymaking studies).

\section{Referências bibliográficas}

AUCOIN, Peter. Administrative reform in public management: paradigms, principles, paradoxes and pendulums. Governance, v. 3, n. 2, p. 115-137, 1990.

BARZELAY, Michael. Breaking through bureaucracy: a new vision for managing in government. Berkeley: University of California Press, 1992.

. The new public management: a bibliographical essay for Latin American (and other) scholars. International public management journal, v. 3, p. 229-265, 2000 .

. The new public management: improving research and policy dialogue. The Aaron Wildavsky forum for public policy. Berkeley, New York: University of California Press; Russell Sage Foundation, 2001.

BATTISTELLI, Fabrizio (Org.). La cultura delle amministrazioni: fra retorica e innovazione. Franco Angeli: Milano, 2002.

BERTALANFFY, Ludwig von. General system theory: foundations, development, applications. New York: G. Braziller, 1969.

BÖRZEL, Tanja. Le reti di attori pubblici e privati nella regolazione europea. Stato e Mercato, v. 54, n. 3, p. 389-432, 1998. 
BRESSER-PEREIRA, Luiz Carlos. Da administração burocrática à gerencial. Revista do Serviço Público, v. 47, n. 1, 1996.

. Democracy and public management reform: building the Republican state. Oxford; New York: Oxford University Press, 2004.

BRUGUÉ, Quim; VALLÈS, Josep Maria. New-style councils, new-style councillors: from local government to local governance. Governance, v. 18, n. 2, p. 197-226, 2005.

CHRISTENSEN, Tom; LAGREID, Per; WISE, Lois. Transforming administrative policy. Public Administration, v. 80, n. 1, p. 153-178, 2002.

DRUCKER, Peter Ferdinand. The practice of management. New York: Harper, 1954. 1974.

. Management: tasks, responsibilities, practices. New York: Harper \& Row,

FAYOL, Henri. Administração industrial e geral: previsão, organização, comando, coordenação e controle. São Paulo: Atlas, 1989.

GUSTAFSSON, Gunnel. Symbolic and pseudo policies as responses to diffusion of power. Policy Sciences, v. 15, n. 3, p. 269-287, 1983.

HAYS, Steven W.; PLAGENS, Gregory K. Human resource management best practices and globalization: the universality of common sense. Public Organization Review, v. 2, n. 4, p. 327-348, 2002.

HOOD, Christopher. The "new public management" in the 1980s: variations on a theme. Accounting, Organizations and Society, v. 20, n. 2/3, p. 93-109, 1995.

; JACKSON, Michael W. Administrative argument. Aldershot, Hants, England; Brookfield, Vt., USA: Dartmouth Pub., 1991.

IMF. The IMF and the good governance. 2003. Disponível em: <www.imf.org/external/ np/exr/facts/gov.htm >. Acesso em: 8 ago. 2006.

JACHTENFUCHS, Markus. The governance approach to European integration. Journal of Common Market Studies, v. 39, n. 2, p. 245-264, 2001.

JONES, Larry R. New public management has been completely discredited, thank God! International Public Management Journal, v. 5, n. 2, p. 148-172, 2004.

KETTL, Donald F. The global public management revolution. 2. ed. Washington, DC: Brookings Institution Press, 2005.

KLIJN, Erik-Hans; TEISMAN, Geert R. Institutional and strategic barriers to public-private partnership: an analysis of dutch cases. Public Money and Management, v. 23, n. 3, p. 137-146, 2003. 
KOOIMAN, Jan. Modern governance: new government-society interactions. Newbury Park, Calif.: Sage, 1993.

LIPSET, Seymour Martin. Some social requisites of democracy: economic development and political legitimacy. American Political Science Review, v. 53, n. 1, p. 69-105, 1959.

MARCH, James; OLSEN, Johan P. Organizing political life: what administrative reorganization tells us about government. American Political Science Review, v. 77, n. 2, p. 281-296, 1983.

MARCH, Robert M. Formal organization and promotion in a pre-industrial society. American Sociology Review, v. 26, n. 4, p. 547-556, 1961.

McCUBBINS, Mathew D.; NOLL, Roger G.; WEINGAST, Barry R. Structure and process, politics and policy: administrative arrangements and the political control of agencies. Virginia Law Review, v. 75, n. 2, p. 431-448, 1989.

McGREGOR, Douglas. The human side of enterprise. New York: McGraw-Hill, 1960.

MERTON, Robert K. Social theory and social structure; toward the codification of theory and research. Glencoe: Free Press, 1949.

OECD. OECD principles of corporate governance. 2004. Disponível em: <www.oecd. org/ dataoecd/32/18/31557724.pdf>. Acesso em: 8 out. 2006.

OLSEN, Johan. The many faces of europeanization. Journal of Common Market Studies, v. 40, n. 5, p. 921-952, 2002.

OSBORNE, David; GAEBLER, Ted. Reinventing government: how the entrepreneurial spirit is transforming the public sector. Reading, MA: Addison-Wesley, 1992.

PARSONS, Wayne. Innovation in the public sector: spare tyres and fourth plinths. The Innovation Journal: the Public Sector Innovation Journal, v. 11, n. 2, p. 1-10, 2006.

PATTON, Michael Quinn. Qualitative evaluation and research methods. Newbury Park, Calif.: Sage, 1990.

PETERS, Tom J.; WATERMAN, Robert H. In search of excellence: lessons from America's best-run companies. New York: Harper \& Row, 1982.

PIERRE, Jon; PETERS, B. Guy. Governance, politics and the state. New York: St. Martin's Press, 2000.

POLLITT, Christopher; BOUCKAERT, Geert. Avaliando reformas da gestão pública: uma perspectiva internacional. Revista do Serviço Público, v. 53, n. 3, p. 5-30, 2002a. 
Editore, 2002b.

. La riforma del management pubblico. Milano: Università Bocconi

RADAELLI, Claudio. If europeanisation is the analytical solution, what is the problem? Looking for the research puzzles in a new field of inquiry. In: CINI, Michelle; BOURNE, Angela (Eds.). The palgrave guide to European studies. Palgrave: Basingstoke, 2005.

REGONINI, Gloria. Paradossi della democrazia deliberativa. Stato e Mercato, v. 73, n. 1, p. 3-31, 2005.

RHODES, Roderick A. W. Understanding governance: policy networks, governance, reflexivity, and accountability. Buckingham, Philadephia: Open University Press, 1997.

RICHARDS, David; SMITH, Martin J. Governance and public policy in the United Kingdom. New York: Oxford University Press, 2002.

SABEL, Charles F. A quiet revolution of democratic governance: towards democratic experimentalism. In: OECD (Organisation for Economic Co-operation and Development) (Ed.). Governance in the $21^{\text {st }}$ century. Paris, 2001. p. 121-148.

SIMON, Herbert A. Administrative behavior: a study of decision-making processes in administrative organization. New York: Macmillan, 1947.

SUBIRATS, Joan; QUINTANA, Imma. Hacia la segunda descentralización en España ¿son los municipios parte de la solución? los claroscuros de la descentralización local. Instituto de Políticas Públicas y Gobierno, Universidad Autónoma de Barcelona, 2005. p. 1-60. ms.

TAYLOR, Frederick Winslow. The principles of scientific management. New York; London: Harper \& Brothers, 1911.

WALDO, Dwight. The administrative state: a study of the political theory of American public administration. New York: Ronald Press 1948.

WEBER, Max. The Protestant ethic and the spirit of capitalism. London: G. Allen \& Unwin, 1930.

. Economy and society: an outline of interpretive sociology. Berkeley: University of California Press, 1978

. The theory of social and economic organization. New York: Free Press, 1992.

WILSON, Woodrow. The study of administration. Political Science Quarterly, v. 2, n. 2, p. 197-222, 1887. 